\title{
A Discovery and Characteristics Description of Telosma puberula (Asclepiadoideae) in Mount Gedang Atas and Mount Ijo, Baturagung Mountain Yogyakarta
}

\author{
Widodo \\ Faculty of Science and Technology, UIN Sunan Kalijaga \\ Jl. Marsda Adisucipto No 1 Yogyakarta 55281, Indonesia. Tel. +62-274-540971, Fax. +62-274-519739
}

Author correspondency:

wwidodo594@gmail.com

\begin{abstract}
Population of Telosma puberula in community forest bushes was identified at S.07.48'.44.1"; E.110.31.15.8", 411m, Mount Gedang Atas and S $07^{\circ} 04$ '04.1"; E $110^{\circ} 30$ '47.9 ", 415m, Mount Ijo. Telosma puberula was also found in Mount Parangan, Mount Mintorogo, Mount Nglanggeran, and Baturagung Mountains Yogyakarta. The identification was based on herbarium specimens collected by Horsfield in 1802 and 1859 from Java Island, Indonesia (K000873052, K000873053). Information about Telosma puberula is very limited. This article describe photographs of morphological characters of the plant's stems, leaves, flowers, and pollinia.
\end{abstract}

Keywords: Telosma puberula, Asclepiadoideae, Mount Gedang Atas, Baturagung Mountains

\section{Introduction}

In an exploration, observation and assessment of wild plants in Mount Gedang Atas Baturagung Mountains in Yogyakarta, the author was collecting fruits of vines from family Apocynaceae, sub family Asclepiadoideae in a community forest at a location of S.07.48'.44.1"; E.110.31.15.8". (Widodo, 411m DPL, 26 September 2012). Furthermore, a specimen collection process and observation was completed in a flowering season in 2013. The same specimen was also found in Mount Ijo within a radius of $5 \mathrm{~km}$ at a location of S.07.47'.04.4 "; E.110.30'.47.9 ". (Widodo, 415m DPL, 31 December 2012). From a thorough identification process using literature and herbarium reviews, it was identified that the specimen collected is Telosma $s p$.

Telosma is belong to Marsdenieae tribe of the subfamily Asclepiadoideae (Takhtajan, 2009: 522). According to Backer and Bakhuizen (1965: 273), there are two types of Telosma in Java: Telosma accedens and Telosma cordata. Meanwhile, Hooker (1885: 38) states that in Java, there is Telosma puberula (a new name for Pergularia puberula). Telosma cordata (a new name for Pergularia odoratissima) is predicted to be a native to China. In Java, the plant has been cultivated as floral fragrance (Backer and Bakhuizen, 1963: 273). Meanwhile Telosma accedens can be found in Central Java, East Java and Madura at an altitude of 10-800 $\mathrm{m}$ in woody shrubs, cleared forests, and teak forests. The previous name of Pergularia accendens was Telosma accedens, Blume. Backer corrected the name into Telosma accedens (B1.) Back. (Backer, 1949: 63). The name Pergularia accedens was firstly published in Bijdragen tot de flora van Nederlandsch Indie (Blume, 1826). The herbarium of Pergularia accedens was collected by Carl L von Blume from the Java island in
1836 (MNHN P03858919). Meanwhile, the herbarium of Telosma accedens Collection (Bl.) Back was collected by CA Backer from the Java island (Jember-Bondowoso) in 1920 (MNHN P03858922).

Studies on Telosma cordata or Tonkin flowers hold are abundant on the internet because this plant is cultivated as floral fragrance plants although there is no identified source from Indonesia. Based on the writer's knowledge, there are no further information or study about Telosma accedens and Telosma puberula in Indonesia after Backer and Bakhuizen (1965: 273), Hooker (1885: 38) and Blume (1836). According to The Plant List (2010), the genus Telosma consists of many species: Telosma accedens (Blume) Backer, Telosma africana (Nebr.) Nebr., Telosma angustiloba (Warb. In Perkins) Merr., Telosma celebica (Warb.) MA Rahman \& Wilcock, Telosma cordata (Burm. F.) Merr., Telosma filipes (Schltr.) MA Rahman \& Wilcock, Telosma pallida (Roxb.) Craib, Telosma procumbens (Blanco) Merr., and Telosma puberula (Miq.) Kerr.

Based on the information obtained from Backer and Bakhuizen (1965: 273) and Hooker (1885: 38), the Telosma species that are available in the Java Island is Telosma accedens, Telosma cordata, and Telosma puberula. There is very little information about Telosma accedens and Telosma puberula both in written literature and published pictures on the internet. This paper attempts to present a description of the characteristics, specimen and herbarium photographs of Telosma specimens found in Mount Gedang Atas and Mount Ijo, Baturagung Mountains. The discovery of the Telosma species in the Baturagung Mountains Yogyakarta needs to be disseminated to present the richness of flora in Java. Wild plants are no longer recognized despite the fact that there were some report in the books of flora and 
herbarium in the past hundreds years by European explorers.

A publication of plant species in the nature is highly needed in attempt to complete the flora world data, to re-check and rediscover old flora, to correct description of the characters for further research in the study of plant biology. The study of Biology is the basis for conservation of earth plants.

The purpose of this study is to present a visual characteristics description of the morphology of leaves, stems, flowers, pollinia, and fruit of Telosma puberula found in Mount Gedang Atas and Mount Ijo, Baturagung Mountains for identification verification.

\section{Materials and Methods}

This research employs one kind of research methode that explores and visits as well as collects data information (exploration and collection trip, (Singh, 1999)). An early exploration was performed in September 2012 along with an exploration of wild plants. Picture taking was completed for the first step of the identification process. Specimen sampling for herbarium was also performed with an awareness of the preservation of the population. Along with the identification process, monitoring and visitation processes were also kept on being conducted based on a prediction on the flowering season and fruit formation, i.e. December 2012, January 2013, March 2013, April 2013, December 2013, and October 2014. Flowers specimen collection was completed using wet preservation technique for further identification.

The tools used for observation and collection were: Sony NEX F3 digital camera, Sony Cyber-Shot DSCW180 digital camera, Canon DSLR digital camera, rulers, micrometers, calipers, small meter roller, plastic for sample collection, scissors, cutter, paper for labeling, GPS (Global Positioning System), dried herbarium collection equipment, flacon bottle, stereo microscope Nikon SMZ 1500 equipped with a camera, Nikon Eclipse 50 light microscope equipped with Nikon DSF1camera. Materials for observation and collection comprise: Aquadest, Alcohol 70\%, FAA (Formalin Acetic Alcohol) solution.

Steps of the study include: (1) photograph the specimens under natural conditions on site, (2) photograph the specimens under the dried herbarium process preparation conditions, (3) photograph the details of the flower, (4) making the dried herbarium, (5) photograph the dried herbarium specimens, (6) collecting and observing the structures of the preserved flowers, (7) observing and photographs the pollinia, (8) early identifying of specimens for the member of Asclepiadaceae based on the book Flora of Java Vol. 2 (Backer and Bakhuizen, 1965), (9) further identifying of specimens for other members of Asclepiadaceae based on existing literature, (10) checking and matching with the herbarium types.

\section{Results and Discussion}

In the exploration, observation and assessment of wild plants in Mount Gedang Atas Baturagung Mountains in Yogyakarta, the author collected fruit from the vines family Apocynaceae sub-family Asclepiadoideae in a community forest located at S.07.48'.44.1" location; E.110.31.15.8" (Widodo, 411m DPL, 26 September 2012). Further, at the initial period of the rainy season at the same location, it was found the shoots with leaves and flowers as such that facilitated further identification S.07.48'.44.1 "; E.110.31.15.8 ". (Widodo, 411m DPL, 31 December 2012). The fruits were initially identified by the author as the fruit of Cynancum callialatum.

Another visit conducted at the beginning of the rainy season 31 December 2012 a set of data was obtained on the habitus and the structure of the specimen because leaves had been grown at the branches and they were flowering. At the same time, an observation at Mount Ijo which is approximately $5 \mathrm{~km}$ from the starting location and the author found the same plants which were also flowering. An identification using the book Flora of Java, Vol. 2 (Backer and Bakhuizen, 1965: 273) mentioned that the plant identified was Telosma. Subsequent visitations and repeated observations were then completed on 19 January 2013 and 29 January 2013 to obtain a complete set of on the plant structure (Figure 1 A, B, C, D, E, and Figure 2). The specimen collection process was carried out in the laboratory for further observation. On 24 March 2013 visit, a young fruit was identified (Figure 4).

Further identification results using the book Flora of Java, Vol. 2 (Backer and Bakhuizen, 1965: 273) showed that this Telosma held the characteristics of Telosma accedens (B1.) Back. A specimen comparison with the 1917 Backer herbarium specimens collection in Java (MNHN P03858922) or Figure 1 F demonstrated the identified specimen compound flower structure of the specimen to be slightly different with the herbarium. The flowers units on the compound stalks converge or congregate in a way so that the compound flower compositions construct a sphere shape, meanwhile the compound flower at the herbarium exhibited characteristics that shaped like a bunch with accompanying braktea (supporting leaves). Another comparison with the Telosma procumbens herbarium specimens collection made by Ramos 1918 from Luzon, The Philippines (MNHN P03858921) it was found that the obtained structure of the compound flower to be similar to the specimen of the identified Telosma but there was a slight difference in terms of the units of flower. A single flower stalk and crown neck tube of the specimen was found to be shorter than that of the Telosma procumbens. The centre of the crown round end when it was still in the form of bud looked much clearer in Telosma procumbens. A comparison of the form and size of the fruit of Telosma procumbens from the Philippines in the United States National Herbarium (USNH623771) collection was the same as the identified specimen but 
the four sides of the fruit wing lines of the specimen identified were more apparent.

From a comparison with the herbarium specimens of Telosma puberula from the Horsfield collection in 1859 of Java (K000873052, K000873053) in Figure $1 \mathrm{G}$, several characteristics were found to be the same in: the flowering type, size of the flower parts and shape as well as size of ovatus-oblong leaves. The sketched figure of pollinia in the Herbarium (K000873053) also showed similarities with the pollinia of Telosma identified in Mount Ijo (Figure 3 A, B).

Characteristics of the pollinia of Telosma puberula foundwere as shown in Figure 3A. The location of the pollinia was upright next to the anther. The shape of the pollinia lobes was ovatus-oblong. The translator were very short. The corpuscullum or caudicle (caudicula) was round egg shaped almost like a short triangle, shiny brown.

A comparison with the herbarium specimens of Telosma puberula collected by Kerr in 1928 from Thailand (MNHN P03858930) was shown in Figure 1H and another one by Petelot in 1941 from Tonkin (MNHN P03858929) there were some characteristics found to be the same in: the structure of compound flower, stalk compound flower, the size of the parts of the flower as well as the shape and size of the leaves.

From the discussions, it was found that the specimen of Telosma from Mount Gedang Atas, Mount Ijo, Mount Parangan, Mount Mintorogo in Baturagung Mountains was Telosma puberulens.
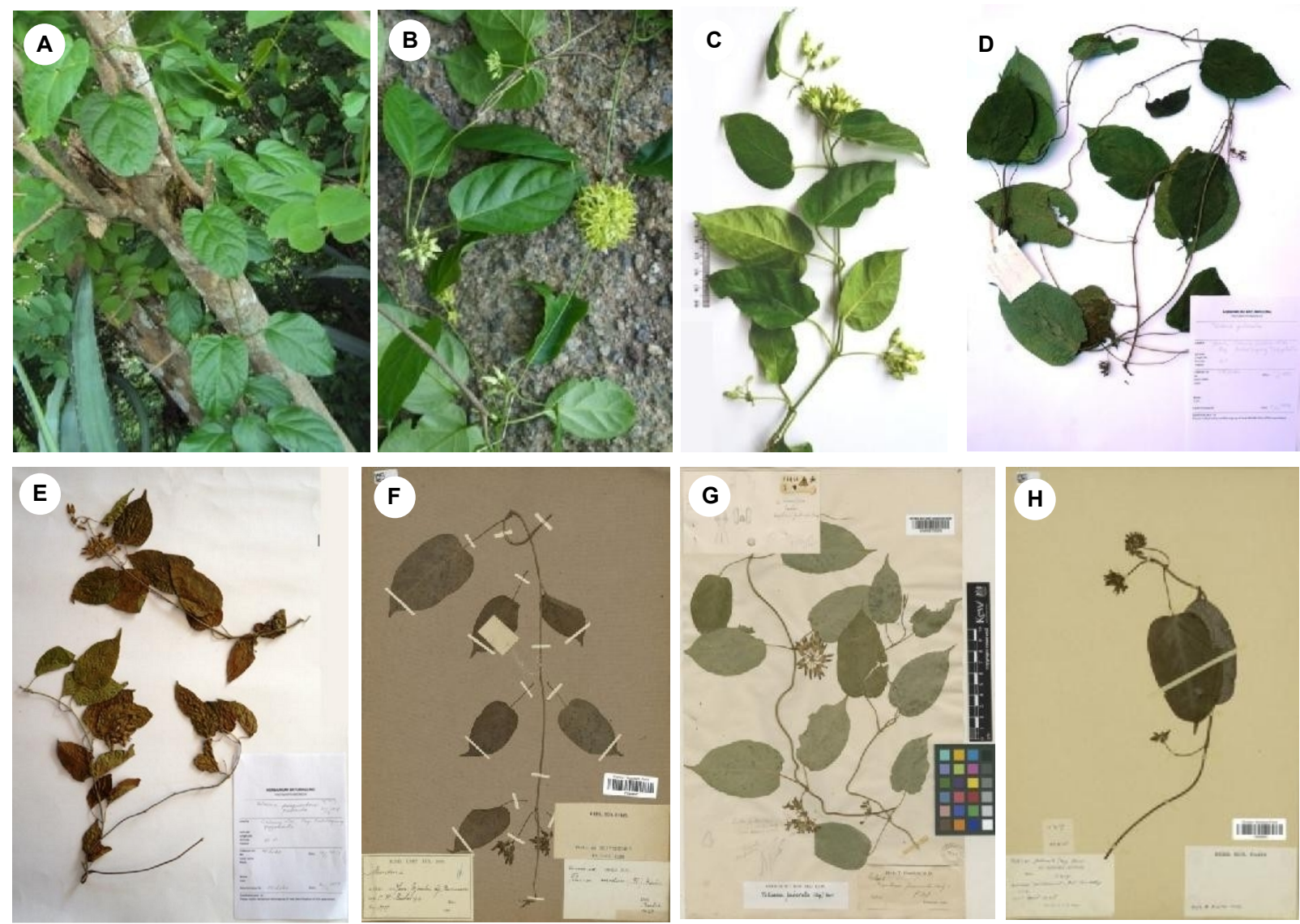

Figure 1. A. Photo Stature (habitus) of Telosma puberula in the Natural Habitat found by the author. B. Flowering Branch of Telosma puberula in the Natural Habitat found by the author. C. Flowering Branch of Telosma puberula under the Laboratory Conditions. D. Herbarium Flower Twig of Young Telosma puberula from The Author's Collection. E. Herbarium of the Blooming Twig Flower Telosma puberula from The Author's Collection. F. Herbarium Type of Telosma accedens (B1.) Back. (MNHN, Paris). G. Herbarium Type of Telosma puberula (Miq.) Kerr. (C copyright of the Board of Trustees of the Royal Botanic Gardens, Kew). H. Herbarium Type of Telosma puberula (Miq.) Kerr. (MNHN, Paris).

\section{Taxonomic information}

Telosma puberula (Miq.) Kerr, Fl. Siam. Enum. 3 (1): 32. 1951; Pergularia puberula Miq, Fl. Brit. India 4: 38. 1885. Type: JAVA, 1802 \& 1859, T. Horfsfield, K000873053, K000873053 (holotype, K!)

\section{Description}

Liana, stem $4 \mathrm{~m}$ or more, smooth surface, young puberulen twigs/branches. $3-6 \mathrm{~cm}$; round-egg shaped to elongated elliptic leaf blade, $6-13 \times 3-8 \mathrm{~cm}$, thin, smooth to the puberulen along the vein, flat base to almost heart shape, tapered tip; lateral veins 4-6 pairs. Extra axillary compound flower, umbrella to round shape, comprising 
several to many flowers; compound flower stems $4-5 \mathrm{~cm}$; flower stalk unit $1-1.5 \mathrm{~cm}$. round-egg shaped petal lobes unit, $2 \times 2.5 \mathrm{~mm}$, slippery until puberulen, slightly hairy edges. bright green or greenish yellow crown, slightly fragrant, crown $1.5 \mathrm{~cm}$ long; crown tube 6-8 $\mathrm{mm}$ long, the tube length is equal to the length of the crown lobe; oblong crown lobes narrowed at the end, 6-8 $\mathrm{mm}$ long, 2-2 mm wide, slightly hairy at the edge tip, yellowish green, rounded ends folded out. Rounded corona tip, folded out; Additional parts of the corona (corollines corona) are higher than the position of pollinia, covering the anthers, pointed tip, thin, yellowish white color. Suboblong pollinia lobe, the half-width long, upright, short triangular corpuscullum, short caudicle. Follicle fruit, 12-18 cm long, 2-3 cm wide, almost rectangular cross-sectional sepal, with four wing lines on the long side; flat seed, round-egg shaped, $1-1.5 \mathrm{~cm}$ in diameter, 4-5 cm seed hair. Flowering season from December to January, Fruit formation: July to September.

\section{Specimens Examined}

Baturagung Mountains, Mount Gedang Atas, S.07.48'.44.1 "; E.110.31.15.8 ", Widodo, 411m DPL, 31/12/2012; Baturagung Mountains, Mount Ijo, S. 07 ', 47 ", 04.4"; E. 110, 30 ", 47.9", Widodo, 415m DPL, $19 / 01 / 2013$.
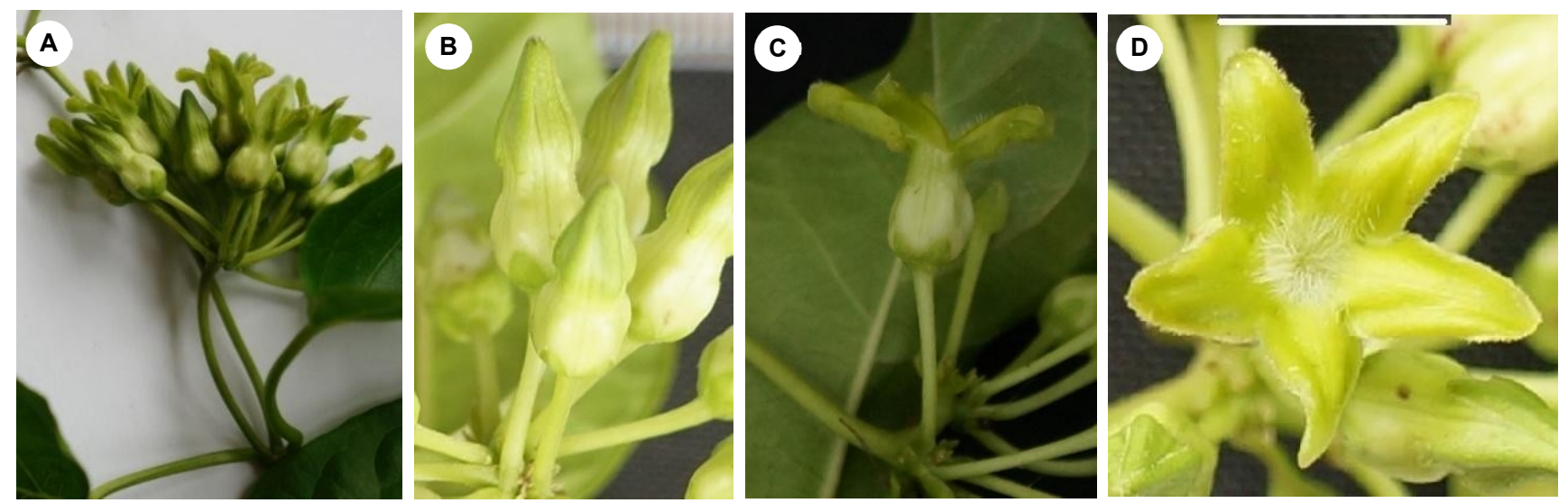

Figure 2. The Structure of Telosma puberula Flower found by the author (A. Compound Flower, B. Flower Buds Unit, C. Blooming Flower Unit (Side View), Unit D. Blooming Flower unit (Top View).
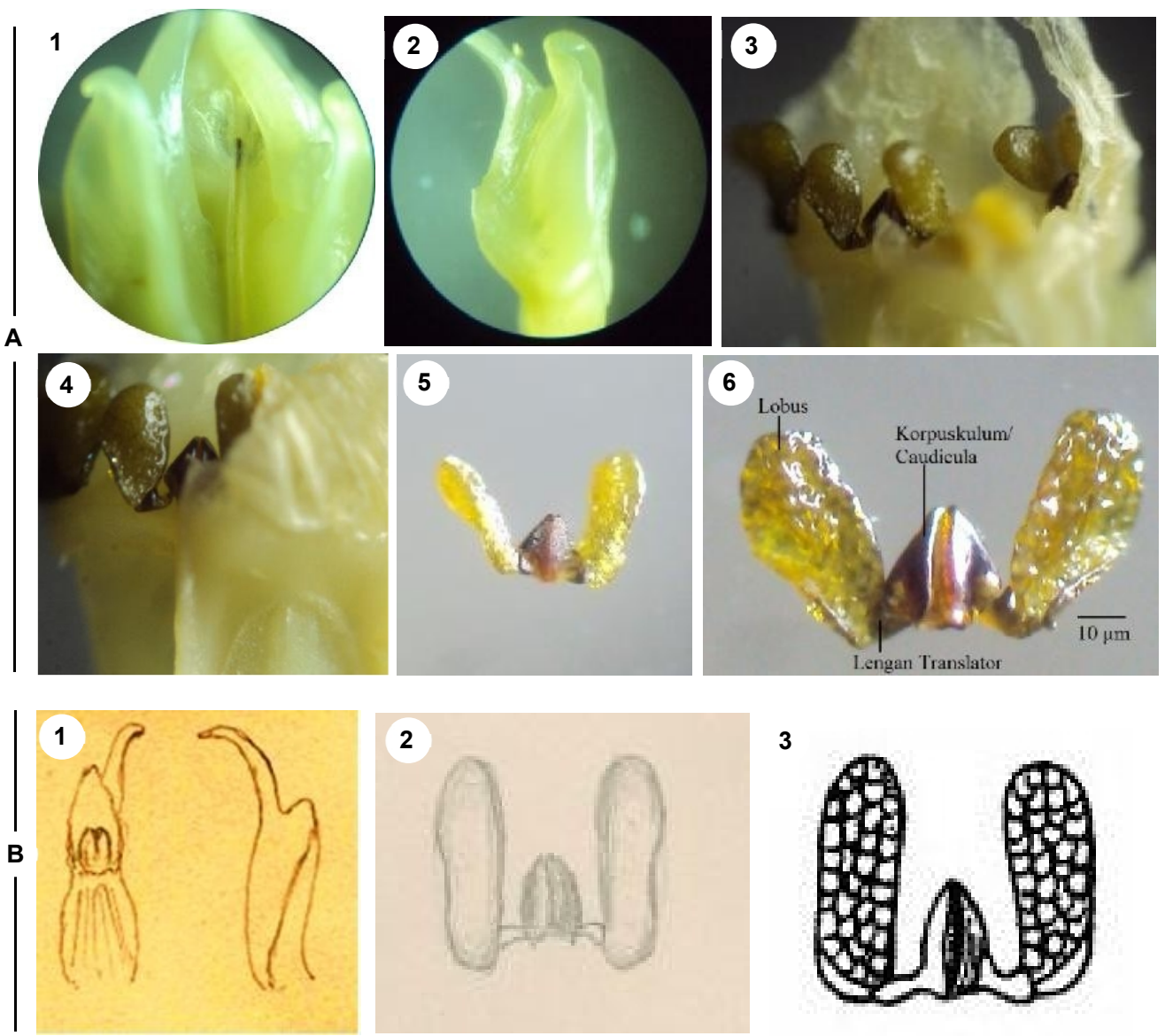

2

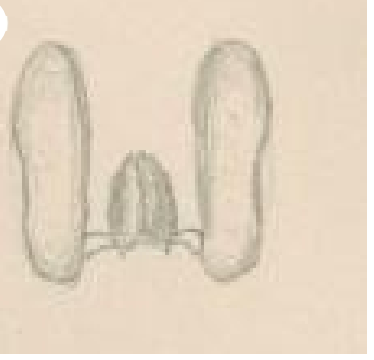

3

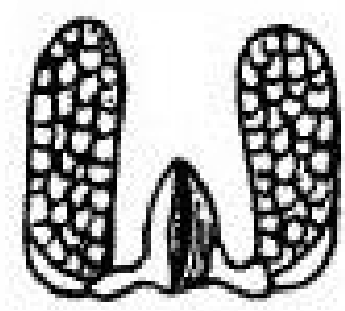

Figure 3. A. The Structure of Gynostegium and Pollinia of Telosma puberula Flower found by the author (1. Gynostegium, 2. Corona and Corollines Corona, 3 , 4. The Orientation or Layout of pollinia, 5, 6. Pollinia Unit and Its Parts. B. Sketched Figure of Parts of Gynostegium and Pollinia of Telosma in Literature (1. Sketch of Corona in the Telosma puberula Herbarium (RBG Kew), 2. Sketch of Pollinia Unit in the Telosma puberula Herbarium (RBG Kew), 3. Satan pollinia Telosma procumbens in the book of Flora of China (1995: 273). 


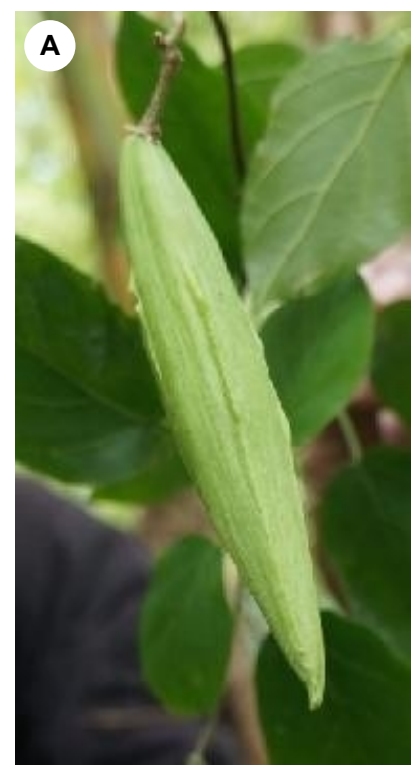

B

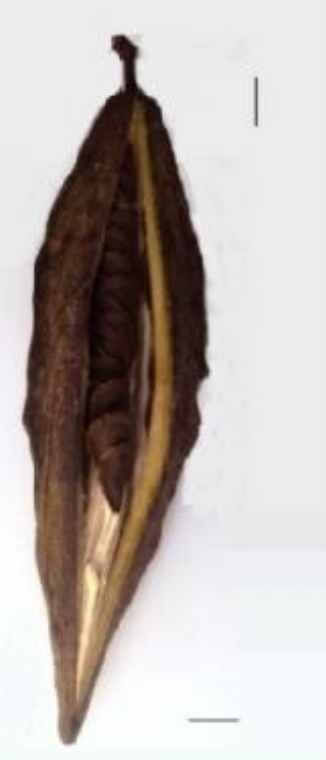

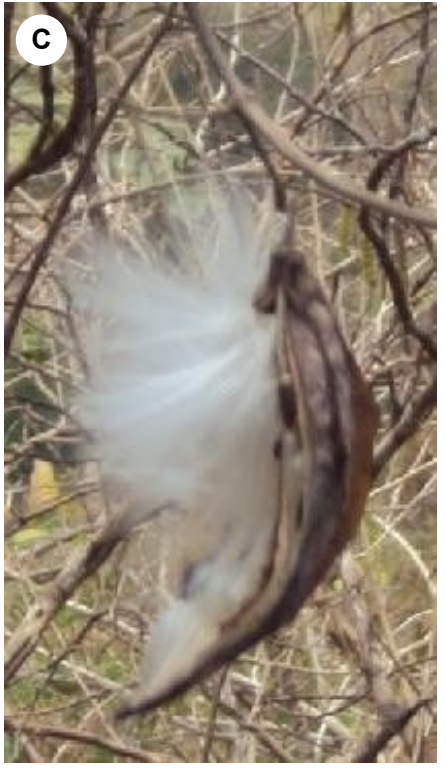

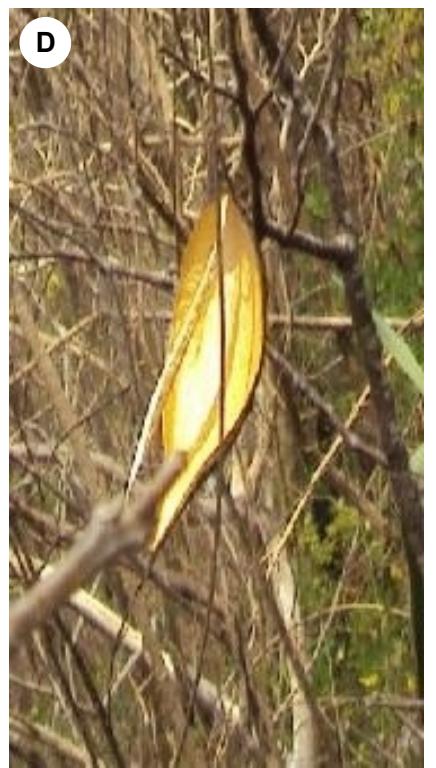

Figure 4. Telosma puberula Fruit Found by The Author. (A. Young Fruit, B. Ripen Fruit, C. Fruit with Seeds and Hairless Seed, D. Wall Fruit After the Seeds Release).

Note

Telosma puberula was found to be twining vines in Cassia fistula and Schoutenia ovata along with other vines, namely: Dioscorea hispida, Dioscorea alata, Vitis trifolia, and Gliricidia sepium. The initial specimen was found by the author during an exploration of the existence of plants of the genus Capparis on site. The author found the Telosma puberula was bearing some fruit on 24 March 2013 in Mount Parangan and Mount Ijo. On 13 April 2013, on the east side of Mountain Mintorogo the author also found Telosma puberula bearing some fruit.

\section{Conservation}

Regarding the limited presence of this plant in the location of the discovery and other locations, it is then necessary to study the status of its cultivation range. Along with the assessment processes, there is a need for live specimen preservations.

\section{Conclusion}

Telosma puberula (Miq.) Kerr was found in Mount Gedang Atas and Mount Ijo, Baturagung Mountains, Yogyakarta. The morphological characteristics of stature (habitus), leaves, of the Telosma puberula flower specimen in Mount Gedang Atas and Mount Ijo shows similarities with the Kew Herbarium Holotype collected by Horsfield in 1802 \& 1859 (K000873053, K000873053) from Java. The existence of Telosma puberula (Miq.) Kerr in Java complete and confirm the descriptions made by Bakhuizen and Backer (1965: 273) on the genus Telosma.

\section{Acknowledgements}

The author would like to express his gratitude to the Herbarium Museum National d'Histoire Naturelle, Paris (MNHN) and the Herbarium Royal Botanic Garden of Kewensis Edinburg (KEW) on the types of herbarium photo credit. The author would also thank Mr. Dr. M. Jafar Luthfi in the Biology Laboratory of UIN Sunan Kalijaga Yogyakarta for his testimony, discussion and confirmation of the discovery of this plant specimen on site.

\section{References}

Backer, C. A. \&Bakhuizen. 1965. Flora of Jawa (Spermatophytes Only).Vol I, II, III. Groningen: N. V. P. Noordhoff.

Backer, C. A. 1949. Beknopte Flora van Java (Nood Unitgave) 8(a. Fam. 173): 63. 1949. http://www.tropicos.org/Name/2609608 accessed 7 October 2014.

Blume, C. L. 1826. Bijdragen tot de flora van Nederlandsch Indië 1056.

Flora of China Editorial Committee. 1995. Flora of China (Gentianaceae through Boraginaceae). 16: 1-479. In C. Y. Wu, P. H. Raven \& D. Y. Hong (eds.) Fl. China. Science Press \& Missouri Botanical Garden Press, Beijing \& St. Louis.http://www.tropicos.org/Image/22 934. accessed 7 October 2014.

Herbarium Museum National d' Histoire Naturelle Paris (MNHN). 2014. Pergularia accedens. http:// colb .mnhn. fr/catalognumber $/ \mathrm{mnhn} / \mathrm{p} / \mathrm{P} 03858919$., accessed 7 October 2014.

Herbarium Museum National d'Histoire Naturelle Paris (MNHN). 2014. Telosma procumbens. http:// colb .mnhn .fr/catalognumber/mnhn/p/ P03858921., accessed 7 October 2014.

Herbarium Museum National d' Histoire Naturelle Paris (MNHN). 2014. Telosma accedens. http:// colb .mnhn $\mathrm{fr} /$ catalognumber $/ \mathrm{mnhn} / \mathrm{p} / \mathrm{P} 03858922$., accessed 7 October 2014. 
Herbarium Museum National d' Histoire Naturelle Paris (MNHN). 2014. Telosma puberula. http:// colb. mnhn. fr/catalognumber $/ \mathrm{mnhn} / \mathrm{p} / \mathrm{P} 03858929$., accessed 7 October 2014.

Herbarium Museum National d' Histoire Naturelle Paris (MNHN). 2014. Telosma puberula. http:// colb. mnhn. fr/catalognumber $/ \mathrm{mnhn} / \mathrm{p} / \mathrm{P} 03858930$, accessed 7 October 2014.

Hooker, J. D. 1885. Flora of British India (Vol. IV). London: Reeve and Co. http://specimens.kew.org/herbarium/K0 00873052. diakses 7 Oktober 2014 http://www.tropicos.org/Name/2602046. accessed 7 October 2014.

IPNI (International Plant Name Index). 2014. Telosma (http:// www. plantsystematics. org, accessed 7 October 2014. Kerr, A.
F. G. 1951. Flora Siamensis Enumeratio 3(1): 32. http:// www. tropicos. org/Name/2609609. accessed 7 October 2014.

Merill, E.D. 1912. Philippine Journal of Science 7: 243. http:// www. tropicos. org/ Name/2607466. accessed 7 October 2014.

Royal Botanic Garden, Kew. 2014. Telosma puberula.

Singh, G. 1999. Plant Systematics. New Hampshire: Science Publisher. Takhtajan, A. 2009. Flowering Plant. St Petersburg: Springer.

The Plant List (2010). Version 1. Published on the Internet; http:// www.theplantlist .org/ tpl/ search?q=telosma + . diakses 7 Oktober 2014.

United States National Herbarium. 2014. Telosma procumbens. https://www. flickr. com/ photos/ filibot/8045825440. accessed 7 October 2014. 